Eeva Kuoppala \& Pekka Uotila

\section{Työelämäpedagogiikka ja tiedon tuottamisen muuttuvat käytännöt}

Ammattikorkeakouluissa pedagogiikka kiinnittyy tiiviisti työelämään. Työelämäpedagogiikka merkitsee $\mathrm{mm}$. verkostoissa toimimista ja erilaisia tiedonhankinnan ja julkaisemisen käytäntöjä. Kirjaston tarjoamat palvelut ovat työelämäyhteyksissä yksi monista palvelumahdollisuuksista. Digitalisaatio ja työelämäpedagogiikka luovat asetelman, jossa julkaisemisen kynnys alentuu. Kirjaston tehtävä "sisältä ulos" -toiminnassa näyttää tässä kehityksessä korostuvan.

$\mathrm{T}$

öelämän nopeat muutokset, misesta. Nykyaikaisen työelämäpedaglobalisaatio ja informaatioyhteiskunnan kehitys ovat moninaistaneet myös korkeakoulujen toimintaympäristöjä (Jääskelä, $\mathrm{Ny}$ känen \& Tynjälä 20I8). Nopeiden yhteiskunnallisten muutosten myötä huomio on kiinnittynyt substanssiosaamisen lisäksi työelämätaitoihin (geneeriset taidot), joita ovat esimerkiksi kriittinen ajattelu, analyyttinen kyvykkyys, ongelmanratkaisukyky ja luovuus (Jääskelä ym. 20I8; The Future of Jobs 2016). Kysymys koulutukselle kuuluukin, miten näitä taitoja käytännössä opetetaan? Yhdeksi lupaavimmista pedagogisista ratkaisuista on osoittautunut työelämäpedagogiikka (esim. Dalrymple, Kenth \& Smith 20I2).

Työelämäpedagogiikan juuret ulottuvat Deweyn I900 -luvun alussa esittämille ajatuksille tekemällä oppigogiikan keskiössä on ajatus oppivista verkostoista ratkaisemassa aitoja työelämän kehittämishaasteita. Työelämäpedagogiikan toimijoina ja oppijoina ovat sekä opiskelijat, opettajat, työelämäkumppanit että korkeakoulujen asiantuntijat. Tässä artikkelissa kuvataan työelämäpedagogiikkaa tämän päivän ja tulevaisuuden osaamisen tuottamisen mallina, sekä tarkastellaan siihen liittyviä uusia tiedon tuottamisen ja käyttämisen muotoja.

\section{Oppiminen tapahtuu} verkostoissa

Työelämäpedagogiikassa oppiminen tapahtuu koulutuksen ja työelämän välisissä tiiviissä yhteistyöverkostoissa, jotka nojautuvat vahvasti jaetun asianuntijuuden ajatukselle (Hakkarainen ym. 2002; Sol ym. 2013; Edwards 20I I; Engeström 20I6). Teoreettista tietoa sovelletaan välittömästi käytäntöön ja ratkaisuja haetaan yhteisöllisen työskentelyn kautta (Kuoppala \& Uotila 20I7). Toimijoiden erilaista asiantuntijuutta hyödynnetään sujuvasti ratkaisujen löytämiseksi. Työelämäyhteyden kautta teoreettinen tieto asettuu kontekstiinsa, mikä puoles taan lisää syväoppimista ja oppimismotivaatiota (Engeström ym. I984 Miettinen I999). Verkostomainen toimintatapa edellyttää verkoston jäseniltä kykyä ymmärtää ja tunnistaa kanssatoimijoiden osaaminen sekä tarjot oma osaamisensa yhteisten päämäärien saavuttamiseksi (Edwards 20 I I)

Suomalaisissa korkeakouluissa työelämäpedagogiikkaa toteutetaan Jääskelän ym. (20 I 8) tutkimuksen mukaan neljän eri mallin kautta: Spesialisti mallin (Specialist Model), Tiedeperustaisen Uudistamisen mallin (Science-based Renewal Model), Projektipohjaisen Integroidun toteutuksen mallin (Project-based Integrative Model) ja Verkottuneen Kulttuurin mallin (Mode of Networked Culture) kautta. Verkottuneen kulttuurin mallia voidaan pitäa edistyneimpänä työelämäpedagogiikan mallia, jossa työelämätaitojen kehittäminen ja työelämäyhteistyö ovat rakenteellinen osa koulutusta. Korkeakoulun toiminnoissa suositaan työelämäyh teyttä ja työelämätaitojen kehittäminen tapahtuu kaikkien koulutuksen toimintojen kautta. (Jääskelä ym. 20 I 8.)

Työelämä rakentuu erilaisista toimintaympäristöistä. Yksi laajalle levin nyt työskentelyn ja organisoitumisen muoto on projekti, jossa tyypillisesti luodaan tilapäinen organisaatio, jonkin tavoitteen saavuttamiseksi. Tällaisess ympäristössä on usein kyse toiminnasta, jossa vaikuttavat monenlaiset toimijat, nopeasti muuttuvat tarpeet ja vaihtelevat tietolähteet (Uotila 20 I I) Yleisemminkin organisoitumista voi daan pitää alati muovautuvana prosessina, josta selviydytään neuvottelemalla (Taylor \& Robichaud 2004). Tällaisissa ympäristössä tapahtuva opiskelu vaikuttaa monin tavoin perinteisiin oppimisen käytäntöihin.

Kirjaston näkökulmasta opiskelu projekteissa ja työelämäkontekstissa muuttaa sekä tiedonhankinnan että julkaisemisen käytäntöjä. Yksittäisen opintojakson aikana tarvittavaa kirjallisuutta ei välttämättä määritellä etukäteen opetussuunnitelmassa, mikä tekee kokoelmien kehittämisestä vaikeaa. Projekti tuottaa itse tietoa ja määrittää, millaista tietoa juuri tässä tilanteessa ja näiden toimijoiden kanssa toimittaessa tarvitaan. Tietoa tuottaessaan projekti osallistaa tekijänsä julkaisemaan tieto tavalla, joka on tyypillistä projekteille, mutta ei välttämättä korkeakoululle.

Tiedon tuottaminen ja käyttäminen

työelämäpedagogiikassa

Työelämään kytkeytyvässä koulutuksessa tiedon rakentaminen vaati opiskelijoiden, työelämän ja koulutusorganisaatioiden asiantuntijoiden välistä yhteistyötä ja jaettua asiantuntijuutta (esim. Hakkarainen ym. 2002). 
Työelämään linkittyneet projektit ja muut oppimistehtävät merkitsevät oppimisen tulosten tulemista laajemmin jaetuksi kuin vain opettajan ja opiskelijan kesken. Tällaisessa kontekstissa voivat asiantuntijuutta edustaa työelämän toimeksiantajat, opettajat ja muut ammattikorkeakoulun asiantuntijat.

Keskeinen työskentelymuoto työelämän ja koulutuksen rajapinnoilla on neuvottelu. Neuvottelun kautta toimijat rakentavat yhteistä toiminnan kohdetta, tuoden jokainen prosessiin oman näkökulmansa ja osaamisensa yhteisen tavoitteen saavuttamiseksi (Miettinen 2005 ). Tässä prosessissa, jossa tuloksena voi olla raportti tai jokin muu dokumentti, on tietoasiantuntijalla tärkeä rooli esimerkiksi tiedon luotettavuuden arvioinnissa, tekijänoikeuksien, pitkäaikaissäilyttämisen ja avoimuuden tuntijana. Vaikka tällaisessa yhteydessä ei kyse ole perinteisessä mielessä julkaisemisesta, tapahtuu työelämäprojektien yhteydessä monenlaista julkista kirjoittamista. Siinä mielessä julkisuuden kynnys on alentunut.

Tiedon hankinnan näkökulmasta työelämään kytkeytyvä koulutus tuo mukanaan asetelmia, jossa samanaikaisesti on käytössä monenlaisia tiedonhankinnan kanavia. Oppilaitoksen tarjoamat ja ylläpitämät palvelut, kuten kirjasto ja sen tietokannat ovat tällaisessa yhteydessä edelleen tärkeitä, mutta eivät kuitenkaan ainoita tiedon hankinnan kanavia. Usein työelämään kytkeytyvä opetus toteutuu monien eri ammattialojen edustajien yhteisis- sä projekteissa. Tällaisessa kontekstissa opiskelijan roolit ja eri aloilla omaksutut käytännöt, myös tiedon hankintaan liittyvät käytännöt, ovat osa tiedon rakentamista ja oppimista.

yöelämäpedagogiikan onnistumisen kannalta on tärkeää, että opiskelijat saavat asiantuntijatukea silloin, kun tiedonhankintaan tai julkaisemiseen liittyvät ongelmat oppimisprosessin aikana ilmaantuvat. Näitä ongelmia saattaa tulla esiin monissa eri yhteyksissä. Opetussuunnitelma ei välttämättä kerro sitä, milloin tiedonhankinnan ja julkaisemisen kysymykset olisi parasta ottaa esille. Tiedonhankina ja omaa lähiyhteisöä laajemmalle yleisölle tehtävää kirjoitustyötä tehdään muissakin yhteyksissä kuin opinnäytetyötä kirjoitettaessa. Yleiset perustiedot tiedonhankinnasta ovat hyvä lähtökohta työelämän kanssa toteutettavissa projekteissa, mutta nopeasti muuttuvissa ja vaikeasti ennakoitavassa toiminnassa entistä tärkeämmäksi näyttäisi muodostuvan tietoasiantuntijoiden rooli yhtenä jäsenenä työelämäprojektien asiantuntijatiimissä.

os korkeakoulukirjastojen toiminnan mieltää kokoelmien näkökulmasta kahtalaiseksi "ulkoa sisälle" - ja "sisältä ulos" -toiminnaksi (Dempsey 20I7) ja jos työelämäpedagogiikan asettaa toiminnan keskiöön, havainnollistuu tiedonhankintaan ja julkaisemiseen liittyvä monimuotoisuus (Kuva I). Työelämäpedagogiikkaa hyödynnettäessä kaikilla (ammatti)korkeakoulutoimijalla on vaihtoehtoja ja neuvottelukump- paneita. Tässä kokonaisuudessa kirjasto on yksi vaihtoehto tiedonhankinnan kanavana ja julkaisemisen asiantuntijana. Työelämäkumppanit voivat suosia sellaisia tiedonhankinnan kanavia, jotka eivät kuulu korkeakoulukirjastojen palveluihin.

\section{Ulkoa sisään}

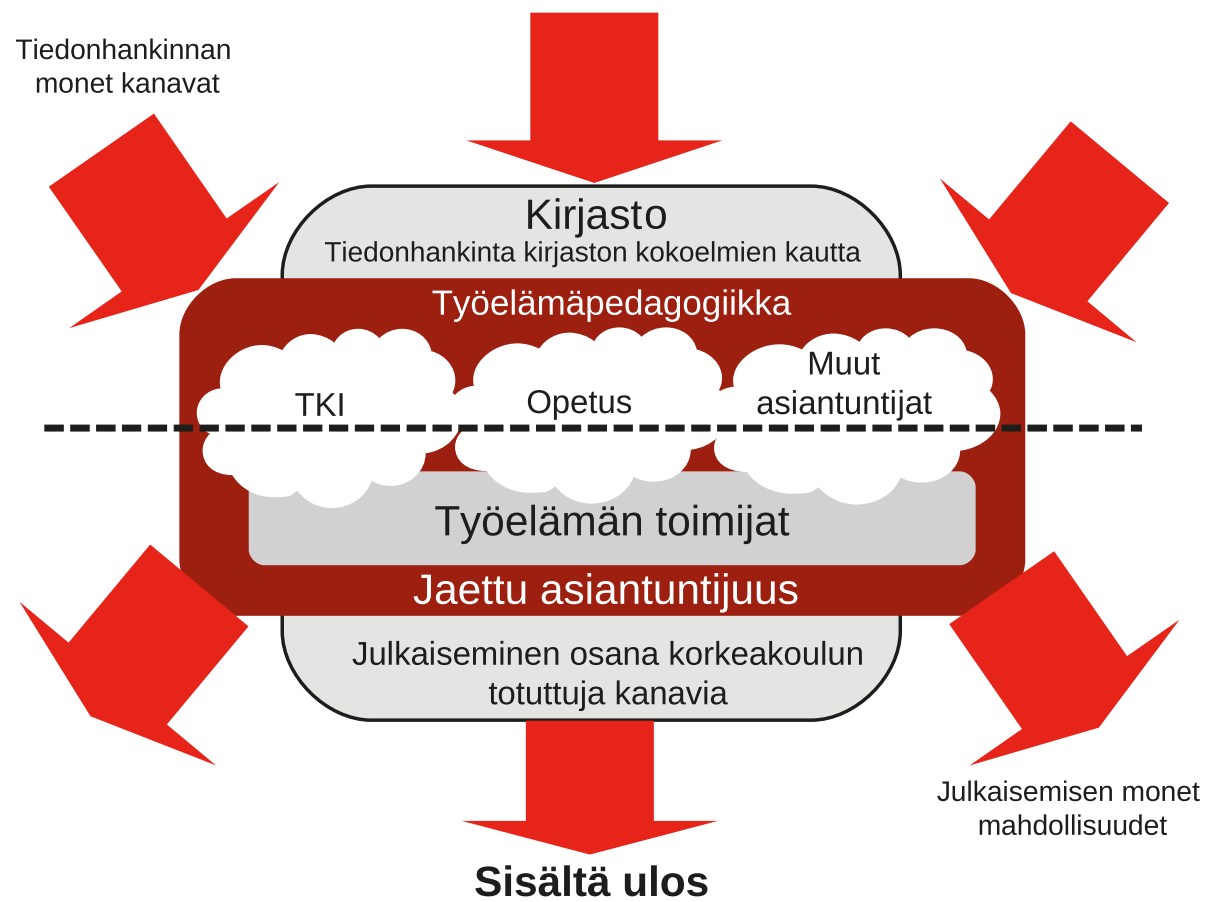

Dempseyn (2017) mukaan kirjaston söä laajemman yleisön. Kirjaston ja logiikka on perustunut painettuun tietoasiantuntijoiden tulisi entistä pakirjaan ja ensisijaisesti kirjaston ul- remmin tuntea sitä todellisuutta, jossa koa-sisään -toimintaan. Digitaalistu- korkeakouluyhteisön jäsenet toimivat. vassa toimintaympäristössä painopiste Kirjaston ja tietoasiantuntijoiden olisi on muuttumassa sisältä-ulos -toimin- oltava entistä syvemmin mukana kortaan. Työelämäpedagogiikka voimis- keakouluyhteisön luovassa toiminnastaa tätä muutosta. Opiskelija tuottaa sa ja tiedon luomisen prosesseissa (vrt. työelämäprojektien yhteyksissä aineis- Lahtinen 2016) toa, joka tavoittaa korkeakouluyhtei- 
Työelämän uutos haastaa korkeakoulun uudistamaan tiedonhankinnan ja julkaisemisen käytäntöjä

yöelämäpedagogiikka heijastaa työelämän yleistä muutosta, jossa työn tekeminen ja oppiminen tapahtuvat yhä enemmän heterogeenisissa ja moniulotteisissa verkostoissa. Yksilön näkökulmasta työelämäpedagogiikka tarjoaa mahdollisuuksia oppia substanssiosaamisen lisäksi myös muita työelämässä tarvittavia taitoja, sekä luoda arvokkaita verkostoja. Opintojen aito työelämäkytkös ja sen vaatimat moninaiset oppimistavat lisäävät usein myös oppimismotivaatiota.

Korkeakouluyhteisön näkökulmasta työelämäpedagogiikka paitsi toteuttaa ammattikorkeakoulujen aluekehitystehtävää myös kasvattaa henkilöstön osaamista jaetun asiantuntijuuden kautta. Verkostoissa oppiminen tapahtuu neuvottelun, tiedon yhteisen rakentamisen ja jakamisen kautta.

Myös kirjaston, sen kokoelmien ja muiden käytänteiden merkitys

\section{Tietoa kirjoittajista}

Eeva Kuoppala

Opetuksen hallintojohtaja,

Kaakkois-Suomen ammattikorkeakoulu eeva.kuoppala@xamk.f

Pekкa Uotila

Kirjastonjohtaja, E-Kampuksen päällikkö,

Kaakkois-Suomen ammattikorkeakoulu pekka.uotila@xamk.fi

\section{Lähteet:}

Dalrymple, R., Kemp, C. \& Smith, P. (2OI4). Characterising work-based learning as a triadic learning endeavour. Journal of Further and Higher Education, 38(1), 75-89.

Dempsey, L. (2017). Library Collections in the Life of the User: Two Directions. Liber Quarterly, 26(4), 338-359.
EDWARDS, A. (20 I I). Building common knowledge at the boundaries between professional practices: Relational agency and relational expertise in systems of distributed expertise. International Journal of Educational Research 50, 33-39.

Engeström, Y., Hakkarainen, K. \& Hedegaard, M. (i984). On the methodological basis of research in teaching and learning. Teoksessa Hedegaard,

M., Hakkarainen, K. \& Engeström, Y. (toim.) Learning and teaching on a scientific basis. Methodological and epistemological aspects of the activity theory of learning and teaching. Aarhus Universitet.

Engeström, Y. (20I6). Studies in Expansive Learning: Learning What Is Not Yet There. New York: Cambridge University Press

Hakkarainen, K, Palonen, T, \& Paavola, S. (2002). Kolme näkökulmaa asiantuntijuuden tutkimiseen. Psykologia, 37(6), 448-464.

JäÄSKelä, P., NyкÄNen, S. \& TYNJÄLÄ, P. (20 I 8). Models for the development of generic skills in Finnish higher education. Journal of Further and Higher Education, 42 (I), I $30-$ I 42.

Kuoppala, E. \& Uotila, P. (20I7). Työelämäpedagogiikka: yhdessä oppimista ja kehittämistä. Next verkkolehti 17.8.2017. Kaakkois-Suomen ammattikorkeakoulu.

Lahtinen, J. (2016). Tietoasiantuntijoiden roolit ja toiminta koulutuksen ja työelämän kehittämishankkeissa. Tapaustutkimus tietokäytäntöjen ja innovatiivisten tietoyhteisöjen kehittämisestä. Tampere University Press.

Miettinen, R. (1999). Transcending traditional school learning: Teachers' work and networks of learning. In Y. Engeström, R. Miettinen, \& R.-L. Punamäki (toim.), Perspectives on Activity Theory. Cambridge: Cambridge University Press, 325-344

Miettinen, R. (2005). Object of Activity and Individual Motivation. Mind, Culture and Activity, I 2(I), 52-69.

Sol, J., BeERs, P. J. \& WALS, A. E. J. (2013). Social learning in regional innovation networks: trust, commitment and reframing as emergent properties of interaction. Journal of Cleaner Production, 49, 35-43.

The Future of Jobs: Employment, Skills and Workforce Strategy for the Fourth Industrial Revolution (20I6). World Economic Forum. https://www.weforum.org/ reports/the-future-of-jobs. Read I.9.I7.

TAYLOR, J. R. \& Robichaud, D. (2004). Finding the Organization in the Communication: Discourse as Action and Sensemaking. Organization I I(3), $395-4 \mathrm{I} 3$

Uotila, P. (20 I I). Projektin suunnittelun narratiivinen rakentuminen. Vaasa: Vaasan yliopisto. 